\title{
Factors Facilitating the Adjustment of Immigrant Children from Zimbabwe in the Foundation Phase to South African Schools
}

\author{
Opeyemi Temilola Adebanji (M.Ed)
}

\author{
St. John's Convent School, Sizanani, South Africa \\ E-mail: opeyemi.temilola@gmail.com
}

\author{
Nkidi C. Phatudi (PhD) \\ Department of Early Childhood Education \\ University of Pretoria, South Africa \\ E-mail: nkidi.phatudi@up.ac.za \\ Cycil G. Hartell (PhD) \\ Department of Early Childhood Education \\ University of Pretoria, South Africa \\ E-mail: cycil.hartell@up.ac.za
}

Doi:10.5901/mjss.2014.v5n3p512

\begin{abstract}
This paper explores the effects of the encounter between the host and home cultures on Zimbabwean immigrant children's acculturation and academic performance in the Foundation Phase in two South African primary schools. The study was qualitative, and made use of case study and narrative inquiry as methodology. Data were collected using interviews, field notes and observation techniques, analysed via document and content analyses. The sample consisted of four immigrant children from Zimbabwe, their parents and teachers. Utilising the communities of practice (Wenger, 1998) and legitimate peripheral participation frameworks, results from the study reveal the following. First, amiable teacher-learner relationships enhanced the adjustment of immigrant children from Zimbabwe in the Foundation Phase to the academic regimen of the schools. Second, adjusting to the school environment can be complicated for immigrant children when they are not acquainted with the language of communication, indigenous South African languages and the academic regimen of the school. Third, linguistically disadvantaged immigrant devised own means of communicating with peers in their communities of practice.
\end{abstract}

Keywords: Immigrant children, cultural adjustment, academic performance, Foundation Phase, Communities of Practice, Legitimate Peripheral Participation.

\section{Introduction}

The Foundation Phase is a significant aspect of a child's academic trajectory (Alexander, Entwisle \& Dauber, 2002). In the South African system of education, the Foundation Phase covers Grades R-3 and it is the first phase of the General Education and Training (GET) band. Children in this Phase are between the ages of six to nine. Yazıcl, Ilter and Glover (2010) suggest that when children go through encouraging events in the Early Childhood stage, they develop good personality and behave in manners consistent with societal values. A number of researchers (such as Turney \& Kao, 2009) have observed that there is paucity of research on the encounters of early childhood migrant children. Generally, the same was observed in South Africa. In particular, Zimbabwean immigrant children were not explored in terms of the impact of their requirement to adjust to novel academic environments and conflicting cultural mores despite their being the largest group of immigrant in South Africa (Tevera \& Zinyama, 2002). It is documented that the manner and magnitude to which humans adjust to the host cultures depend on the individuals and their home country (Berry, 1986; Trickett \& Birman, 2005). Immigrant children have been reported to naturally negotiate their position within the host society. These children are however confronted by multiple challenges; some of which may include language, new culture and the requirement to associate with learners who are not ready to assist them in alleviating their linguistic challenges (Von Grünigen, Perren, Nagele \& Alsaker, 2010). Children schooling in a country different from theirs often 
confront various obstacles which they have to surmount in order to attain academic excellence and integrate into their society of sojourn (Millar, 2011). The effect of the encounter between the host and home cultures on Zimbabwean immigrant children's academic performance in the Foundation Phase therefore requires investigation. It becomes important to understand how teachers in the Foundation Phase assist them to adjust to the classroom environment in ways that foster their settlement and acquiescence with scholastic requirements.

One of the most prominent changes immigrant children have to go through is adjusting to a culture which is at variance with their home culture. Immigrant children are often challenged by the pursuit of finding a balance between home and host cultural injunctions. In a study conducted by Mac and Alderson (2009) on Chinese immigrants in Canada, participants shared their stories in retrospect of their childhood experiences when they first immigrated to Canada. They recalled that one of the things they had to contend with was adjusting to the Western Canadian culture which was at variance with their Chinese culture. This situation brought about a dilemma regarding their need to find a point of stability between the two cultures. This study therefore presents a platform to explore the effect the South African culture has on immigrant children from Zimbabwe in the Foundation Phase and the extent to which these immigrant children adjusted to the South African culture.

Another hurdle entails the notion that immigrant children are predisposed to growing "up with strong ties to two countries, two cultures, and two ways of being, which can produce multiple realities, multiple ways of being and communicating with the world" (Rodriguez, 2009, p. 17). This study thus explores the consequence of immigrant children from Zimbabwe growing up with strong affiliation to two terrains, dissimilar cultures, diverse comportments and interacting with their worlds of operation. Rodriguez (2009) also suggests that teachers are not often prepared to engage immigrant children in scholarly matters because they come from backgrounds not known to them. Consequently the preparedness of teachers to teach cross-culturally at the research sites was problematized to explore their involvedness in the academic profile of the immigrant children from Zimbabwe in the Foundation Phase. These issues in literature therefore generate the research question which is subsequently stated: What are the factors affecting the successful adjustment of immigrant children from Zimbabwe in the Foundation Phase to South African schools?

\section{An Exploration of the Extant Literature}

In an attempt to explore the research problem, an exploration of literature was subsequently conducted to reveal the dynamics at work as far as the movement of immigrants to other countries is concerned.

\subsection{Dynamics of immigration, associated challenges and opportunities}

All over the world, there are various reasons for the movement of people from one country to another. These include war situations in their usual countries of residence and the search for better living conditions (Cornish, Peltzer \& MacLachlan, 1999; Ottaviano \& Peri 2005; Plender, 1986; Sookrajh, Gopal, \& Maharaj, 2005). With the exit of the apartheid system of government in South Africa, the country's borders were opened to various categories of African immigrants. Consequently, South African immigration policies presented opportunities to different people looking for favorable means of survival (Weiner \& Munz, 1997). According to Baubock, Heller and Zolberg (1996) the movement of people to another country emanates from their perception that there are ample opportunities in their target destination. However these opportunities are usually laden with challenges involving how to acculturate to novel cultures. Particularly, their children are required to negotiate linguistic transition from their local languages to the mainstream linguistic demands (Sookrajh, Gopal \& Maharaj, 2005). A complication to the linguistic transition of immigrant children from Zimbabwe involves the use of 11 official languages in South Africa. Sookrajh et al. (2005:6) contend that the influx of immigrants seems to be enhanced by the attention and fostering bestowed on their children. In some cases they are given school uniforms and track suits on arrival at the school. At times they are exempted from paying school fees, once they are able to prove their immigrant status. South Africa now signifies a terrain of prospect for black immigrants in search of better living standards, but their stay may not be devoid of challenges (Crush, 2008). The adjustment of immigrant groups to the novel society has been indicated to be dependent on their country of origin and certain associated constraints and opportunities they confront. These may range from the degree of belonging to the extent of discrimination experienced by the immigrant children in the new society (Leyendecker \& Lamb, 1999). These issues propel the drive to investigate the dimensions of opportunities and challenges confronting immigrant children from Zimbabwe in the Foundation Phase. They also provide the opportunity to explore their acculturative tendency in the midst of the available mainstream offerings, both at the school and home fronts. 
Many immigrant groups have been reported to exhibit bicultural tendencies, where they adjust to the novel culture without giving up their original culture (Portes, 1996; Rumbaut, 1995). This study perceives that immigrant children may not be capable of choosing their affiliation to one or more cultures, except at the expense of their immigrant parents. We conceptualize that their choice in terms of cultural preference may be informed by the commitment of their parents to ensure their compliance with home-front cultural principles. According to Portes (1996), a number of immigrant groups are resolved to maintain their cultural identities, by being reluctant to negotiate their home cultures with the cultures of the host society. If this is the case with the immigrant children from Zimbabwe in the Foundation Phase, we infer that their parents led them into doing so. Cultural adjustment may be predicted when immigrant children in a novel society indicate their extent of membership to their preferred culture (Berry, 1995; LaFromboise, Coleman, \& Gerton, 1993). This entails a dialogic process where certain perspectives of the immigrant's indigenous and novel cultures intermingle to form a new and unique dimension of conduct, mindset and way of life (Jain \& Belsky, 1997).

The extent of adjustment of immigrant children to a new culture can be deciphered by looking at their ability to learn the language of communication in the host society. Sookrajh et al. $(2005$, p. 11) found that immigrant children learn the mainstream language, ethnic society values and the way of life of the mainstream society more briskly than grownups. According to Yeh, Okubo, Ma, Shea, Ou and Pituc (2008) communication is paramount to the adjustment of immigrant children in a new society. Communication is enhanced through language (Soto, 1997) as language is an essential tool for interaction, both in the classroom and on the play field (Gupta, 2009). Reacting to this scholarly output, it would imply that the ease with which the immigrant children from Zimbabwe in the Foundation Phase use English or the indigenous South African language to communicate, would be regarded as their being on course as far as acculturation is concerned. Consistently, in her study of four Korean children in an Australian lower primary school, Millar (2011, p. 15) observed that the adjustment of children to the school environment depended mainly on "actual and perceived" language inadequacy. Perceived language inadequacy may be responsible for incapability to interact with peers during play due to inability to communicate in the broader language.

It has been observed that many immigrant children experience discrimination when they are not adept in the mainstream language (Souto-Manning, 2009). Also, incompetence in the use of the local language predisposes immigrant children to victimization in the midst of their indigenous peers (Von Grünigen et al., 2010, p. 688). Moreover the extent of belonging of immigrants to the society of sojourn may be used as a measure of their adjustment to their host country (Berry, 1986). Billman, Geddes and Hedges (2005) acknowledge that belonging provides support for children to survive in their environment and fosters full achievement of their potential. Sense of belonging also indicates the degree of attachment to the school and the entire learning that culminates as a result of this (Wenger, 1998). This is because, learning subsumes every experience that the immigrant children are exposed to, both scholarly and non-academic (Wenger, 1998). Interaction of children with their peers in the classroom and on the play field generates learning experiences which are acquired, though, informally (Gupta, 2009). Asanova (2005, p. 191) posits that two salient factors initiate a sense of belonging, capable of fostering identity; how teachers relate to students and the outlook of the school administration and staff to diversity. It has been observed that children's sense of belonging is enhanced when they are aware that their peers and adults with whom they relate at the school and within the community are concerned about their welfare (Agbenyega \& Peers, 2010). An exploration of learner-teacher relationship is conceptualised in this study to predict the extent of belonging of immigrant children from Zimbabwe in the Foundation Phase to their school and the effect it may have on their cultural predisposition as it influences their academic performance.

Children commonly undergo a complicated course of adjustment in their evolution from a known terrain to a novel one. Adjusting to the school environment can be complicated for children when they are not acquainted with the cultural mores of the host society. This is because adjustment depends on their ability to decode information required to maneuver in mini-systems or "early childhood context" (Vidali \& Adams, 2007, p. 124). Sanagavarapu (2010) suggests that it becomes imperative for educators in public schools to be aware of the necessity of helping immigrant children to have a hitch-free navigation to the school community and their host society. This process of change may be more complicated for children who have come from a background of multiple cultures and languages such as immigrant children from Zimbabwe who are the focus of this study. In the case of South Africa with so many ethnic predispositions, the encounter between the Zimbabwean and South African cultures may produce certain novel insights capable of informing the tactics required to ensure that immigrant children are well nurtured in their bid to blend with the prevailing culture. Consequently sense of belonging, learner-teacher relationships, the outlook of the school administration and staff to diversity, actual and perceived languages of communication are presented as predicaments in this study. 


\subsection{Cultural adjustment and academic welfare}

Mantovani and Martini (2008) propose that one of the ways to determine the welfare of immigrant children in their host society is how well they are doing at school with regard to their academic attainment. Traditionally, the school provides instructional knowledge and educational opportunity. In addition to this, the school also acts as an agent of transmission of cultural values and norms of the society. It has been reported that the application of instructional methods that consider disparities in cultural inclinations and the participation of the minority appear to achieve better academic performance in the classroom (Ryan, Casas, Kelly-Vance, Ryalls, \& Nero, 2010). Villenas and Deyhle (1999, p. 432) reflect the same phenomenon. In an ethnographic study on the Latino schooling and family education, they assert that "a lack of motivation" may grow "out of repeated negative school experiences." The school is thus an important social setting where learners develop association with one another in an influential way that may have bearing on learning behaviour and ambition which consequently impact on academic performance (Bygren \& Szulkin, 2010).

Academic wellness among immigrant children may be measured using such factors as: final grade results, incidences of class repetition and time taken to complete school (Mantovani \& Martini, 2008). Eng, Kanitkar, Cleveland, Herbert, Fischer and Wiersma (2008) in their study of school achievement among Chinese and Filipino American students predicted disparity in educational accomplishment based on ethnicity and parental participation. Immigrant youths who participated in Eng et al.'s (2008) study were observed to reduce their attachment to their home cultures and values as they gravitate towards higher integration into the majority culture. This had a great implication for educational achievement of the immigrant students. James and Martin (2009), in a study conducted on the comparison of the parentchild interactions among Russian immigrant and non-immigrant families within a rural milieu in Missouri found that educators within the rural setting often struggle with immigrant children who engage in learning a second language. This suggests that academic achievement may be hindered in immigrant children who need to learn a second language, especially as language of instruction in the academic institution. These findings present the opportunity to explore the ongoing cultural practices at the home front of immigrants and at the school. Drawing on Wenger (1998) we conceptualised the effort of parents in terms of motivation as a subset of home front communities of practice. Therefore parents work in favour of the school front communities of practice, comprising teachers and the intervention of the school management. In the same vein the effort of teachers, as they relate to the immigrant children also constitutes communities of practice with the immigrant children in the midst of their peers, engaged in learning together. We speculate that the effort of teachers in terms of how they relate to the immigrant children could assist in their adjustment to scholarly and social principles at school. To elucidate an understanding of the communities of practice principle adopted in this paper, we discuss the communities of practice framework, in terms of its versatility at unravelling the dynamics at work between home and school front dynamics.

\section{Theoretical Framework}

Communities of practice theory was used as framework to comprehend the exploration of factors facilitating the adjustment of immigrant children in the Foundation Phase to South African schools.

\subsection{Communities of practice}

Traditional learning theories conceived learning as unidirectional, individual-bound and rigid. However communities of practice as proposed by Wenger (1998) conceptualise learning as located within communal and the usual environments of learners. It therefore implies that learning in communities of practice emphasizes the importance of interaction among community members rather than on individuals. Papadopoulou and Birch (2009) draw our attention to the fact that when learning is situated within a social context, learners cannot be viewed as separate from their secular world, of which they are part. It means that the fact that immigrant children from Zimbabwe are physically present within their social and academic environment would create lived experiences in physical and emotional dimensions. It is conceptualised in this study that these experiences are such that they are difficult to disregard because the immigrant children from Zimbabwe would be actively involved in the process of learning within the COP. In this regard the immigrant children from Zimbabwe are regarded as newcomers to the communities of practice at school, engaging in learning the tenets therein. At the home front they are also regarded as newcomers born into the family, learning from their parents and receiving the necessary cultural capital and motivation necessary to adjust to novel cultures. Learning in this context goes beyond acquiring information to granting them access centripetally to the core of the community until they become experts. As 
the immigrant children advance towards the core of the communities, they come into contact with other members of the community from whom they learn the tenets and mores. This makes learning interactional. Barab, Barnet and Squire (2002, p. 495) describe communities of practice as groups of people who are communally reliant and accommodate jointly expressed cultures and repertoire within a specified dimension of time in search or acquisition of a collective goal or achievement. In this context the collective goal may involve the learning undertaken by Zimbabwean immigrant children in the midst of indigenous and other stakeholders in the learning community. A learning community is a group of individuals who engage in specified activities, share a set of attributes or a concern regarding a subject matter, and who entrench their understanding and insight in these joint concerns by associating with one another within a specified time dimension (Wenger, McDermott \& Snyder, 2002, p. 4).

A community itself has been defined as a social setup where concerns are outlined as valuable to pursue and the involvement of participants is identifiable as competency (Wenger, 1998, p. 4). According to Wenger (1998, p. 122), learning in communities of practice is vital because it changes the identity and expertise of participants. It is expected therefore that the impact of cultural adjustment on Zimbabwean immigrant learners would transform them to the point of attaining an identity. This is because learning does not just entail the gathering of expertise and the knowhow, but the course of attaining an identity (Wenger, 1998). As Wenger (1998, p. 122) sees it, it is conceptualized that when immigrant children arrive at a society of settlement, they tend to shift their position as they interact with other members of the community via multifaceted involvement in the communities of practice. As they interact it is conceptualized that opportunities to learn within the context of the community are created in the continuum.

From literature it is important to note that cultural adjustment cannot be considered without identity, due to their involvedness and interdependence (Yeh et al., 2008). Identity shifts may ensue if there is any attempt to deny "access" capable of "limiting centripetal movement of newcomers" into the community. Such shifts may tend to distort the learning curriculum of the community (Wenger, 1998, p. 122-123). By inference from the available literature perused so far (e.g., Chow, 2006; Yeh et al., 2008), linguistic challenges may deter "centripetal" movement of immigrant children within the communities of practice. This study provides a platform of investigation among Zimbabwean immigrant children in the Foundation Phase, especially, finding the effects of "centripetal" movement within the learning community.

Lave and Wenger describe the key point of belonging as suggested by other researchers (e.g., Asanova, 2005; Gay, 2000; Osterman, 2000) by perceiving the initiation of learning "as legitimate peripheral participation", thus implying "that learning is not merely a condition for membership" in a community of practice "but is itself an evolving form of membership" (1991, p. 53). This theory provides a platform for understanding the events within the immediate environment of immigrant children from Zimbabwe in the Foundation Phase, by looking at the effect their new communities will have on them. Language is seen as the entry point of negotiation. When the level of linguistic integration is low on the periphery of access, the extent of interaction between novices and experts may become a concern because interaction to attain a set identity may be adversely affected. To comply with the suggestion of Lave and Wenger (1991, p. 53) the only perceivable circumstance that fosters learning would be in terms of initiating communication that tends to lead to opening an avenue of interaction between newcomers and experts until learning becomes "an evolving form of membership." Learning would become an "evolving form of membership" when members of the community reach the point of comprehending the tenets of the community as participation is further triggered in a centripetal direction until full participation is reached.

In communities of practice interactional engagements provide opportunities for learning. This idea is substantiated by Piirainen-Marsh and Tainio, (2009). They focused on additional language learning as embedded in membership, in the communal activity of cooperative game-play. It was reported that participation provided the opportunity for members (players) to use English, thus adding the language to their catalogue of communication. Learning was noted to have been mutually constructed among participants and viewed as a route of negotiating meaning and knowledge. They also highlighted the role of repetition and imitation. Repetition and imitation improved the understanding of members of current events and created a standpoint on their interests. Consequently this study presents an insight into the extent to which participation and interaction between indigenous and Zimbabwean immigrant learners in the Foundation Phase promotes learning in such a manner that fosters cultural adjustment with consequent influence on their academic performance.

\section{Research Strategy}

This study made use of case study design. According to Yin (1984) a case study is a practical inquiry designed to explore an existing event, in its natural context, where there is a clear-cut boundary between the event and perspective, with the 
use of diverse sources of information. In this case study research approach, attention was given to specific illustrations of learning experiences with the intention of accessing hypothetical, proficient and deep understanding arising from documented evidence of particular illustrations, drawing on Freebody (2003, p. 81). Cohen, Manion and Morrison (2007, p. 254) propose that case studies could be employed to describe "what it is like" to operate in a particular scenario in order to catch a glimpse of what naturally exists in the real world of research subjects using diverse data sources. A natural context, as it relates to this study, comprises studying immigrant children from Zimbabwe in their natural and familiar environments (their homes and the schools where they attend). This way, a high degree of divergence is not demanded of them "from the place(s) they are used to, what they usually do or who they are usually with" (Mukherji \& Albon, 2010, p. 26). Participants were selected from two schools identified to have Zimbabwean children in the Foundation Phase (purposive sampling). The first parent to indicate interest in participating in the research introduced us to other parents who participated in the study (snowball sampling).

\subsection{Research participants}

The research participants constituted four immigrant children from Zimbabwe in the Foundation Phase, drawn from two primary schools. They were aged between six and seven. In addition four parents and three teachers were interviewed one-on-one. All the children were born in Zimbabwe before their parents came to South Africa. Their parents had lived in South Africa for more than two years. All the children were living with both parents.

\section{Data Collection}

Data were collected using observation of the children. Interviews were conducted with the children, their parents and teachers. Document analysis also constituted data source.

\subsection{Data collection procedure}

Data collection began after obtaining ethical approval from the University Ethics Committee, the Department of Education, the school principals, Schools' Governing Bodies and parents of the immigrant children. Children's assent was obtained by involving their parents who read the letter of assent and explained it to their children. Parents chose to sign the letter of assent on behalf of their children after they gave their consent to participate in the study. The children, parents and teachers were interviewed on one-on-one basis. The interviews were semistructured in nature. Questions were already prepared to be used as a guide to channel the course of the interview. The interview protocol for the children consisted of questions in three sections, which were; biographical information, schooling experiences and identity. Questions were asked in a way that was comprehensible and age-appropriate for the children. The questions put to parents bordered on their personal experiences in South Africa, their children's schooling experiences and their stances toward the South African culture. The main focus of questions put to the teachers was on their individual experiences with the immigrant children from Zimbabwe in the Foundation Phase.

The children were observed inside their classrooms and also during playtime on the play field. Observation protocol was prepared in advance as a guide in the various observable aspects of the phenomenon. Observable phenomena such as classroom atmosphere, interaction between learners and teachers, and interaction between immigrant children and the indigenous children were documented in the observation journal. Visits were made to each school two days in a week for three weeks.

\subsection{Data analysis}

Data analysis progressed concurrently with the data gathering process. Data obtained from the interviews were transcribed to identify key information emerging from the interviews. Responses from the interviews were compared with what was recorded in the observation journal. The portions that were identified to give answers to the research questions were coded, and the emerging themes identified and analysed, as suggested by Coffey and Atkinson (1996, p. 32). Pseudo names given to the children are Tommy, Dave, Chester and Nicholas. 


\section{Findings and Discussion}

Narratives obtained from the immigrant children from Zimbabwe, their parents and teachers who taught them were used to present the adjustment dynamics of immigrant children from Zimbabwe in the Foundation Phase. These factors are hereby discussed.

\subsection{Sense of belonging and swift adaptation to the school environment}

All the immigrant children who participated in this study were found to be coping with their academic environment. However this adjustment was not instant, but after a period of time. The initial struggle encountered by them was voiced by Tommy's teacher. She spoke thus: At first it's difficult for them but as time goes on they change and cope with what their friends are doing. From her point of view the immigrant children did not experience adjustment difficulties. Corsaro, Molinari and Rosier (2002) posit that children construct and participate within the tenets of their distinct cultural domain by innovatively accessing information within their immediate environment. They argue that they (children) do this in an attempt to deal with their immediate concerns. As was found during our observation sessions with the immigrant children from Zimbabwe, their concerns were in the direction of wanting to belong to the school environment as they participated in the groups of the other children. We found that this aspect of belongingness was initiated by the innateness present within them to associate and partake in academic and social configurations at the school. For example when an inquiry was made from Dave to decipher whether he found peace in the academic institution, he said "I have fun with my friends". Utilising the communities of practice framework, the immigrant children operated within the communities of practice comprising indigenous South African children and children from other countries. There were no acts of discrimination among the children. Consequently the immigrant children from Zimbabwe blended with the other children by learning how they operated at the school. The absence of discrimination likely gave them the freedom to acquire a sense of belonging to the school. These findings concur with Wenger (1998) that there are subdivisions of communities of practice which work together amicably for learning to evolve in a larger community of practice (the school environment). As the immigrant children approached the school they legitimately and peripherally began to participate in the different communities of practice comprising teachers, South African children and the immigrant children from other African countries. We agree with Leyendecker and Lamb (1999) that the adjustment of immigrant groups to the novel society depends on the extent of discrimination experienced by the immigrant children. The other issue we could not ascertain was the influence of country of origin on their sense of belonging, which Leyendecker and Lamb implicated as requirement for the adjustment process. We argue that immigrant children seldom experience harsh adaptation constraints in the Foundation Phase.

\subsection{Adequate linguistic capital}

Basic understanding obtained from the available evidence reveals that the comprehension of the language of instruction paved the way for the academic success of immigrant children from Zimbabwe in the Foundation Phase. This line of argument is presented based on the fact presented by Dave's teacher concerning Dave. She said "His work is lovely, his English is beautiful and he always understands things before I explain to him". This provides evidence that adeptness in English facilitated Dave's quick adjustment to curriculum content. Similarly Nicholas and Tommy were found to have achieved academic excellence because they understood English. Our observation while in their classrooms made sense that they adjusted to the school environment. They spoke English very well and understood tasks given to them. Nicholas' teacher attested to his brisk adjustment to the school by saying:

This boy also didn't have problem with language because he was in the crèche before, here in this area and they were speaking English in the crèche. So that helped him to cope with his academic work.

Nicholas' teacher identified prior learning of English at the Crèche as an important factor in the experience of Nicholas at the school. Dave's ability to effectively communicate was initiated by the commitment of his parents to speaking in English with him at home before he began to attend the primary school. The effort of his parents was responsible for his prior learning of English. At the crèche Nicholas and Tommy belonged to communities of practice which used English to communicate. These communities of practice support the argument of Wenger (1998) that subdivisions of communities of practice work together for learning to ensue. Dave's parents symbolized home front communities of practice, working together with him to learn English. The effort at the home front communities of practice 
enhanced his potential to cope at the school due to prior learning of English. We reiterate that when parents deliberately use English to communicate with their children at home, their children are empowered to participate in communities of practice at school. Furthermore communities of practice who adopt a common language in line with the language policy of academic communities of practice have synergistic effect on participants' learning trajectory.

\subsection{Amiable teacher-learner relationship}

The rapport between the teachers and immigrant children from Zimbabwe in the Foundation Phase facilitated their adjustment to the academic environment. The rapport ensued in dimensions that culminated in commendable integration. It also resulted in substantial academic achievement. All the immigrant children from Zimbabwe who participated in this study seemed to enjoy good relationship with their teachers. For example when Dave was asked how much he liked his teacher, he responded "I like my teacher very much, and I enjoy mathematics as a subject". Similarly, Chester fondly retorted "I like my teacher because she teaches me everything." These were evidence of adjustment to the school environment in readiness for learning to take place as a result of the amiable relationship between these learners and their teachers. These experiences likely manifested themselves because of the expert-novice relationship in communities of practice as suggested by Lave and Wenger (1991). Teachers at the schools (experts) constituted communities of practice, as suggested by Wenger (1998, p. 108), providing the opportunity for learners to acculturate and have a sense of belonging for learning to ensue. This likely took place by virtue of the teacher-learner relationships which were positive. These experiences support the work of Asanova (2005, p. 191) that "the quality of teacher relationships" with learners enhances their adjustment to the school environment.

\subsection{Parental influence}

The parents of Tommy, Dave and Nicholas endeavoured to communicate with their children in English. They did this to assist them to make a swift adjustment to the school community. This practice assisted the children in the process of learning to master the use of English. This finding supports Chow's (2006, p. 109) claim that "proficiency in English is a major consideration in the necessity, rapidity, and ease with which immigrants adapt to a milieu dominated by English." Similarly this study's finding with respect to the craving to learn English by immigrants seems to support Rodriguez (2009, p. 18) that "learning English becomes the most important goal for the children of immigrants to attain" in the society of sojourn that has chosen English language as the language of instruction at school. Consequently the parents of immigrant learners from Zimbabwe chose to incline the understanding of their children in the direction of learning the English language at home because of the future goal that they set for them to proficiently communicate in English in an attempt to adjust to the sociocultural diversity of the South African schools which they attended. We compared the input of Chester's parents in terms of their lack of commitment at home to communicate with him in English to the parents of the other three immigrant learners. We found that Chester's parents did not engage him in communication with English. This lack of commitment affected him to the point that he could not speak English at all. Chester's teacher began to use another Zimbabwean learner in class to teach him curriculum content. She did this by pairing Chester with this other Zimbabwean learner who was vast at speaking both English and Shona (an indigenous language spoken by Zimbabweans). This Zimbabwean learner who understood English and Shona code switched as he communicated with Chester in class. The effort of Chester's teacher reveals the idea of what we term as "linguistic communities of practice", an avenue adopted to reach Chester with curriculum content. This practice further strengthens the notion of Wenger (1998) that subdivisions of communities of practice are capable of effecting learning among its participants. This study also reiterates the possibility of instituting linguistic communities of practice among its members. We suggest the creation of linguistic communities of practice to support learning among linguistically disadvantaged learners as was done by Chester's teacher. Consequently we equate the role played by Chester's teacher as a miniaturized parental role aimed at revamping him from his state of incommunicado. Therefore when home front communities of practice become dysfunctional by not preparing children to make the necessary linguistic transition required at school, the effort of teachers becomes relevant by creating linguistic communities of practice to aid the required transition for learning to ensue.

\subsection{Unique intrinsic charisma}

It is obvious that among the four immigrant children that were explored in this study, Chester was the only one found to 
have academic challenge. As suggested by Yeh et al. (2008), Chester's experience was firsthand evidence that diminished communication in the LoLT is capable of slowing down the adjustment process of immigrants to the society of sojourn. However he had the charisma to associate with his peers despite not being capable of speaking English or any of the South African languages. Nevertheless the sense of belonging which he had, did not translate into academic achievement because of the absence of a common language of communication required for academic learning to take place. Chester's linguistic insolvency provided evidence that seems to support the scholarly input of Yeh et al. (2008) that English language comprehension is a tool that assists immigrants to comprehend academic work. However Chester's ability to decode what was spoken by his indigenous South African peers without being capable of speaking English or any of the indigenous South African languages seems to depart from the other aspect of Yeh et al.'s (2008) finding that the English language is important for communicating in the novel society. This aspect of their finding is a diversion from the findings of this study. We were puzzled at Chester's capacity to decode information from his indigenous South African peers despite his inability to speak any of the indigenous languages and English. Chester's inability to verbally communicate with his peers seemed to continue to the point that he began to explore avenues of interacting with his peers in his own devised ways. As stated above in the previous section we are only able to positively implicate his participation in the linguistic communities of practice, inaugurated by his teacher as the starting point where he gathered the effrontery to decode information without the correct capital to verbalize his thoughts as he played with his peers. It is argued that outgoingness and ability to fight the barrier of language among immigrant children seem to break the insurgence that could arise against them in terms of the possibility of exclusion from the academic environment. This argument seems to suffice when the relationship between the sense of belonging and academic performance is considered. Chester was found with the charismatic capital which seemed to have given him a sense of belonging. It is theorized that as immigrant children who are linguistically challenged gather the capacity to rise above the challenges of linguistic incapability, a stage could be reached when they begin to make sense of utterances that they project among themselves to the point of understanding the communication between them and their peers. We argue that at such instances, body language during the process of communication becomes important. It is also presumed that Chester understood his peers despite his inability to speak either English or any of the indigenous South African languages by decoding the body language of his peers as they played together at the school.

Such a dimension of learning to decipher information is categorised in this study as informal learning, which leads to the ability of children to handle non-academic information. It is also theorized that Chester's informal ways of deciphering information among his peers could not make him cross over to academic mode of knowing and retrieving information in an academic environment because such information could only be intellectually processed and deciphered. Therefore it is argued in this study that the capacity of children to associate and adjust to an academic environment, despite their linguistic challenge may not translate to improved academic performance, but to having a sense of belonging to the academic environment which is capable of aiding their adjustment.

\section{Conclusion}

This study shows that there are several factors capable of assisting the adjustment of immigrant children from Zimbabwe in the Foundation Phase. None of the Zimbabwean immigrant learners who participated in this study seemed to experience adjustment difficulties into the South African society. At the school they enjoyed amiable relationships with their teachers - symbol of professionalism. The immigrant learners also benefited in terms of an amiable association with their indigenous South African peers. The fact that Chester did not speak nor proficiently comprehend English did not deter him from associating with his friends. This was an indication that, among immigrant learners in the Foundation Phase, language may not be a barrier to associating and relating with their indigenous peers. They mixed freely with their peers without any fear of hatred or discrimination. It was observed in literature (e.g. Berrigan, Forsyth, Helba, Levin, Norberg, \& Willis, 2010) that the sense of belonging of immigrants can be measured by racial mix of age cluster with which immigrant children spend their leisure time. Chester's case indicates that diminished comprehension of English may not be a barrier in adjusting to the social environment of the school. However this may present possible barrier in adjusting to the school curriculum, to the extent of hindering academic achievement. The community of practice framework provides the opportunity to understand the roles and obligations of experts towards newcomers. As newcomers take strides into the community of practice via legitimate peripheral participation, they become conversant with the curriculum of the community. The absence of discrimination and acts of xenophobia were instrumental to the brisk adjustment of immigrant learners from Zimbabwe in the Foundation Phase to the schools. This gives us the unction to add that communities of practice would function more efficiently where there is absence of discrimination and acts of 
xenophobia. Members would thus be able to freely learn and integrate briskly into the tenets of the community of practice. Chester's story challenges the communities of practice framework because he blended socially with peers despite not being able to speak English or any of the traditional languages. His charisma and outgoingness likely offered him the privilege of adjusting to the communities of practice without a language of communication. Therefore we posit that charisma and outgoingness may predispose immigrant children to adjusting to societal mores. However such adjustments may not translate to academic advantage because a language of communication is required to decipher the curriculum.

\section{Recommendation}

Early childhood educators therefore need to create circumstances through which immigrant children who arrive in an English dominated milieu can benefit from learning English language. Based on the findings of this study it is recommended that private and public schools should embark on a remedial programme that could foster the linguistic capacity of immigrant children. This could be done by creating special classes aimed at linguistically empowering immigrant children to cope with academic matters before being introduced to mainstream learning programmes. In addition programmes should be incorporated into the school curriculum to train teachers in the Foundation Phase on how to manage the multicultural classroom with its attendant challenges. This may alleviate the concerns of Rodriguez (2009, p. 18) that teachers are not always prepared to teach immigrant students in multicultural milieus.

\section{References}

Agbenyega, J., \& Peers, C. (2010). Early childhood inclusion: A silver lining in the dark clouds for African immigrant children? International Journal of whole schooling, 6(2), 46-58.

Alexander, K. L., Entwisle, D. R., \& Dauber, S. (2002). On the success of failure: A reassessment of the effects of retention in the primary grades (2nd. ed.). New York: Cambridge University Press.

Asanova, J. (2005). Educational experiences of immigrant students from the Former Soviet Union: A case study of an ethnic school in Toronto. Educational studies, 31(2), 181-195.

Barab, S.A., Barnett, M., \& Squire, K. (2002). Developing an empirical account of a community of practice: Characterizing the essential tensions. The Journal of the Learning Science, 11(4), 489-542.

Baubock, R., Heller, A., \& Zolberg, A. (Eds.) (1996). The challenge of diversity: Integration and pluralism in societies of immigration. Aldershot: Avebury.

Berrigan, D., Forsyth, B.H., Helba, C., Levin, K., Norberg, A., \& Willis, G.B. (2010). Cognitive testing of physical activity and acculturation questions in recent and long-term Latino immigrants. BMC Public Health, 10:481.

Berry, J.W. (1986). The acculturation process and refugee behavior. In C.L. Williams \& J. Westermeyer (Eds.). Refugee mental health in resettlement countries (pp. 25-37). Washington, D.C: Hemisphere.

Berry, J.W. (1995). Psychology of acculturation. In N.R. Goldberger \& J.B. Veroff (Eds.). The culture and psychology reader (pp. 457488). New York: New York University Press.

Billman, N., Geddes, C., \& Hedges, H. (2005). Teacher-parent partnerships: sharing understandings and making changes. Australian Journal of Early Childhood, 30(1), 44-48.

Bygren, M., \& Szulkin, R. (2010). Ethnic environment during childhood and the educational attainment of immigrant children in Sweden. Social Forces, 88(3), 1305-1330.

Chow, H.P.H. (2006). Vietnamese-Canadian university students in Regina: Socio-cultural and educational adaptation. Canadian Ethnic Studies, 38(2), 104-112.

Coffey, A., \& Atkinson, P. (1996). Making sense of qualitative data. Complementary research strategies. Thousand Oaks/London/New Delhi: Sage Publications Inc.

Cohen, L., Manion, L., \& Morrison, K. (2005). Research methods in education (5th ed.). London: Routledge Falmer.

Cornish, F., Peltzer, K., \& MacLachlan, M. (1999). Returning strangers: The children of Malawian refugees come 'home'. Journal of Refugee Studies, 12(3), 265-283.

Corsaro, W.A., Molinari, L., \& Rosier, K.B. (2002). Zena and Carlotta: Transition narratives and early education in the United States and Italy. Human Development, 45, 323-348.

Crush, J. (2008). South Africa: Policy in the face of xenophobia. Southern African migration project (SAMP).

Eng, S., Kanitkar, K., Cleveland, H.H., Herbert, R., Fischer, J., \& Wiersma, J.D. (2008). School achievement differences among Chinese and Filipino American students: acculturation and the family. Educational Psychology, 28(5), 535-550.

Freebody, P. (2003). Qualitative research in education: Interaction and practice. London. SAGE.

Gupta, A. (2009). Vygotskian perspectives on using dramatic play to enhance children's development and balance creativity with structure in the early childhood classroom. Early Child Development and Care, 179(8), 1041-1054.

Jain, A., \& Belsky, J. (1997). Fathering and acculturation; Immigrant Indian families with young children. Journal of Marriage and the 
Family, 59, 873-883.

James, J.L., \& Martin, B.N. (2009). A comparison of the parent-child interactions between Russian immigrant and non-immigrant families in a rural setting in Missouri. The Rural Educator, 30(2), 11-19.

LaFromboise, T., Coleman, H.K., \& Gerton, J. (1993). Psychological impact of biculturalism: Evidence and theory. Psychological Bulletin, 114, 395-412.

Lave, J., \& Wenger, E. (1991). Situated learning: Legitimate peripheral participation. Cambridge: Cambridge University Press.

Leyendecker, B., \& Lamb, (1999). Latino families. In M. Lamb (Ed.). Parenting and child development in non traditional families. Mahwah, New Jersey: Lawrence Erlbaum Associates.

Mac, L.L., \& Alderson, K.G. (2009). A conceptual model of the retrospective accounts of Chinese adults who immigrated to Canada as children. Canadian Ethnic Studies, 41(1),115-135.

Mantovani, D., \& Martini, E. (2008). Children of immigrants in Trento: Educational achievement through the lens of friendship. Intercultural Education, 19(5), 435-447.

Millar, N. (2011). Korean children's cultural adjustment during transition to the early years of school in Australia. Australasian Journal of Early Childhood, 36(3), 10-18.

Mukherii, P., \& Albon, D. (2010). Research methods in early childhood: An introductory guide. Londen: SAGE.

Ottaviano, G.I.P., \& Peri, G. (2005). Rethinking the gains from immigration: Theory and evidence from the U.S. NBER Working Paper Series, available on http://www.nber.org/papers/w11672.

Papadopoulou, M., \& Birch, R. (2009). Being in the World: The event of learning. Educational Philosophy and Theory, 41(3).

Piirainen-Marsh, A., \& Tainio, L. (2009). Collaborative game-play as a site for participation and situated learning of a second language. Scandinavian Journal of Educational Research, 53(2), 167-183.

Plender, R. (1986). Recent trends in national immigration control. International and Comparative Law Quarterly, 35, 531-566.

Portes, A. (1996). What shall I call myself? Hispanic identity formation in the second generation. Ethnic and Racial Studies, $19,523-547$.

Rodriguez, T. (2009). Schooling and language learning in a transnational context. The High School Journal, 16-33.

Rumbaut, R. (1995). The new Californians: Comparative research findings on the educational progress of immigrant children. In R. Rumbaut \& W.A. Cornelius (Eds.), California's immigrant children: Theory, research, and implications for educational policy (pp. 17-69). San Diego:

Ryan, C.S., Casas, J.F., Kelly-Vance, L., Ryalls, B.O., \& Nero, C. (2010). Parent involvement and views of school success: the role of parents' Latino and white American cultural orientations. Psychology in the Schools, 47(4), 391-405.

Sanagavarapu, P. (2010). Children's transition to school: Voices of Bangladeshi parents in Sydney, Australia. Australasian Journal of Early Childhood, 35(4), 21-29.

Sookrajh, R., Gopal, N., \& Maharaj, B. (2005). Interrogating inclusionary and exclusionary practices: Learners of war and flight. Perspectives in Education, 23(1), 1-14.

Soto, L.D. (1997). Language, culture and power: Bilingual families and the struggle for quality education. New York: State University of New York Press.

Souto-Manning, M. (2009). Acting out and talking back: negotiating discourses in American educational settings. Early Childhood Development and Care, 179(8), 1083-1094.

Tevera, D., \& Zinyama, L. (2002). Zimbabweans who move: Perspective on international migration in Zimbabwe. The Southern Africa Migration Project, Migration Policy Series 25.

Trickett, E.J., \& Birman, D. (2005). Acculturation, school context, and school outcomes: Adaptation of refugee adolescents from the former Soviet Union. Psychology in the Schools, 42(1), 27-38.

Turney, K., \& Kao, G. (2009). Barriers to school involvement: Are immigrant parents disadvantaged? Journal of Educational Research, 102(4), 257-271.

Vidali, E.L., \& Adams, L.D. (2007). A challenge of transnational migration: Young children start school. In L.D. Adams \& A. Kirova (Eds.). Global migration and education. London: Lawrence Erlbaum Publishers.

Villenas, S., \& Deyhle, D. (1999). Critical race theory and ethnographies Challenging the stereotypes: Latino families, schooling, resilience and resistance. Curriculum Inquiry, 29(4), 413-445.

Von Grünigen, R., Perren, S., Nagele, C., \& Alsaker, F.D. (2010). Immigrant children's peer acceptance and victimization in kindergarten: The role of local language competence. British Journal of Developmental Psychology , 28, 679-697.

Weiner, M., \& Munz, R. (1997). Migrants, refugees and foreign policy: Prevention and intervention strategies. Third World Quarterly, 18, 25-51.

Wenger, E. (1998). Communities of practice: Cambridge, England. Cambridge University Press.

Yazıcı, Z., İlter, B.G., \& Glover, P. (2010). How bilingual is bilingual? Mother-tongue proficiency and learning through a second language. International Journal of Early Years Education, 18(3), 259-268.

Yeh, C.J., Okubo, Y., Ma, P.W., Shea, M., Ou, D., \& Pituc, S.T. (2008). Chinese immigrant high school students' cultural interactions, acculturation, family obligations, language use, and social support. Adolescence, 43, 172, 775-790.

Yin, R.K., (1984). Case study research: Design and methods. Newsbury Park, CA: Sage. 